\title{
THE ROLE OF COORDINATION IN CATALYTIC REDOX PROCESSES
}

\author{
K. B. YATSIMIRSKII \\ The Institute of Physical Chemistry, Academy of Sciences of the \\ UkrSSR, Prospect Nauki 97, Kiev 28, USSR
}

\begin{abstract}
Nearly all redox processes involve the formation of a 'precursor' complex as a first stage. The conditions under which the 'precursor' complex is formed have been formulated and a role of the symmetry of interacting orbitals has been established. The classification for oxidizing agents has been proposed. The oxidizing and reducing agents are roughly divided into: $d$-oxidants and $d$ reductants and s.p-oxidants and s.p-reductants. The former react rapidly with each other, while the latter react slowly. The types of the catalysts used have been examined. Two most important mechanisms of catalytic redox processes have been discussed: an alternate oxidation and reduction of the catalyst and complex formation between catalyst and substrate. It has been found that the catalytic activity of a catalyst differs depending on the form of its existence in solution. Quantum chemical patterns have been suggested to account for the activation of a ligand due to its coordination.
\end{abstract}

During the last decade the kinetics and mechanism of redox processes have been rather widely discussed in literature. Suffice it to mention several monographs dedicated to this problem and some extensive sections in other monographs dealing with mechanisms of redox reactions ${ }^{1-5}$.

Nevertheless, the role of coordination in catalytic redox processes has not yet been satisfactorily elucidated and the present paper is an attempt to consider the problem from the point of view of coordination chemistry.

It has been established ${ }^{3,6}$ that a great majority of redox processes proceed according to a three stage mechanism:

1. The precursor complex formation by oxidant and reductant species:

$$
\begin{aligned}
\mathrm{A}+\mathrm{B} & =[\mathrm{A} \ldots \mathrm{B}] \\
\mathrm{Ox}_{1}+\operatorname{Red}_{2} & =\left[\mathrm{Ox}_{1} \ldots \operatorname{Red}_{2}\right]
\end{aligned}
$$

2. The electron transfer in which the 'precursor complex' is converted into a 'successor complex':

$$
\begin{aligned}
{[\mathrm{A} \ldots \mathrm{B}] } & =[\mathrm{X} \ldots \mathrm{Y}] \\
{\left[\mathrm{Ox}_{1} \ldots \operatorname{Red}_{2}\right] } & =\left[\operatorname{Red}_{1} \ldots \mathrm{Ox}_{2}\right]
\end{aligned}
$$

3. The dissociation of the 'successor complex' which results in the final reaction products:

$$
\begin{aligned}
{[\mathrm{X} \ldots \mathrm{Y}] } & =\mathrm{X}+\mathrm{Y} \\
{\left[\operatorname{Red}_{1} \ldots \mathrm{Ox}_{2}\right] } & =\operatorname{Red}_{1}+\mathrm{Ox}_{2}
\end{aligned}
$$




\section{K. B. YATSIMIRSKII}

In all cases the overall process can be expressed as:

$$
\begin{aligned}
\mathrm{A}+\mathrm{B} & =\mathrm{X}+\mathrm{Y} \\
\mathrm{Ox}_{1}+\operatorname{Red}_{2} & =\operatorname{Red}_{1}+\mathrm{Ox}_{2}
\end{aligned}
$$

Reaction 4 must of course, be feasible on thermodynamic grounds, i.e. the redox potential difference must be sufficient to allow its occurrence.

In the precursor complex the vacant orbital of the oxidant and the reductantfilled orbital must overlap one other. The distances between A and B for such overlapping must be fairly small, in order that these two species can interact or, there must be, at least, a possibility of their close contact.

It is possible to formulate the following three conditions for the formation of the precursor complex:

1. Orbital overlapping $\left(s=\left\{\varphi_{\mathrm{A}} \cdot \varphi_{\mathrm{B}}>0\right)\right.$

2. Electrostatic interaction between $\mathrm{A}$ and $\mathrm{B}$ or, at least, very weak electrostatic repulsion.

3. A small difference in the coulombic integrals of donor and acceptor orbitals $\left(H_{\mathrm{A}}-H_{\mathrm{B}} \simeq 0\right)$.

The following species may be examples of 'precursor complexes':

$\left[\mathrm{Fe}^{\mathrm{III}} \mathrm{I}^{-}\right](p K=1.88), \quad\left[\mathrm{Fe}^{\mathrm{III}} \mathrm{NCS}^{-}\right](p K=3.0)$,

$\left[\mathrm{Fe}^{\mathrm{III}} \mathrm{S}_{2} \mathrm{O}_{3}^{2-}\right](p K=2.10), \quad\left[\mathrm{Fe}^{\mathrm{III}} \mathrm{ArOH}\right], \quad\left[\mathrm{Cu}^{\mathrm{II}} \mathrm{I}^{-}\right]$,

$\left[\mathrm{Cu}^{\mathrm{II}} \mathrm{NCS}^{-}\right](p \mathrm{~K}=2.10), \quad\left[\mathrm{Cu}^{\mathrm{II}} \mathrm{ArNH}_{2}\right], \quad\left[\mathrm{V}^{\mathrm{V}} \mathrm{I}^{-}\right], \quad\left[\mathrm{V}^{\mathrm{V}} \mathrm{ArOH}\right]$,

$\left[\mathrm{V}^{\mathrm{v}} \mathrm{ArNH}_{2}\right], \quad\left[\mathrm{Ce}^{\mathrm{IV}} \mathrm{I}^{-}\right], \quad\left[\mathrm{Ce}^{\mathrm{IV}} \mathrm{NCS}^{-}\right], \quad\left[\mathrm{Co}^{\mathrm{III}}(\mathrm{OH})_{2}\right],\left[\mathrm{M}^{n+} \mathrm{O}_{2}\right]$ etc.*

Precursor complexes have been established and studied only for very few redox processes. Many redox processes have not been studied at all from these standpoints.

Precursor complexes can be of different nature: the real coordination compounds within rather a wide range of stability, the charge transfer complexes $^{8}$, the species with contacting orbitals in which the Van der Waals forces act, or very short-lived species (contact charge transfer complexes) even without such interaction.

The use of special techniques makes it possible to elucidate the nature of precursor complexes in many cases.

There are several theories concerned with the mechanism of electron transfer in precursor complexes and these fall into two main classes: theories assuming a continuous reorganization of reactants until the final state is reached (corresponding to an adiabatic electron transfer) and those assuming electron tunnelling (non-adiabatic processes). The 'harpoon model' seems to be a limiting case of this second type of electron transfer. It was successfully used for the interpretation of some results in molecular beam studies of the reactions between alkali metal atoms and halogen molecules". The "harpoon model' and 'charge transfer complex formation' seem to have the same mechanism of electron transfer.

Nevertheless, in all cases orbital overlapping is a necessary condition in electron transfer processes.

\footnotetext{
* The values of the stability constants are taken from ref. 7 .
} 
There are at least three main types of overlapping of reductant and oxidant orbitals (Figure 1$)^{8}$. The $\sigma$ type of overlapping is the most usual one and it can be observed in many cases involving different types of atomic orbitals $(s, p, d)$.

The $\pi$ type of overlapping is especially important for the $d$ orbitals of oxidant or reductant species.

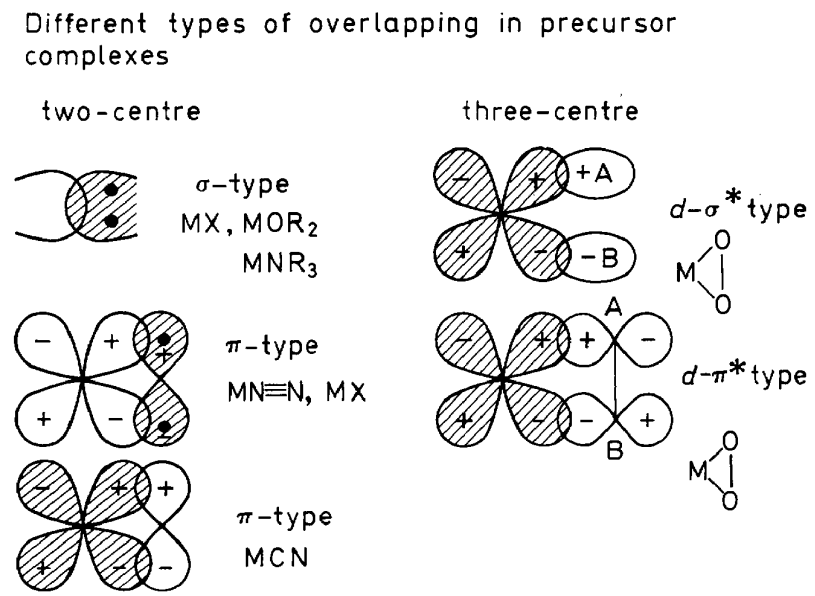

Figure 1. Types of overlapping of oxidant and reductant orbitals

A third type of overlapping includes at least three atomic orbitals, i.e. the overlapping of $d$ orbitals with $\sigma$ antibonding or $\pi$ antibonding orbitals in molecules of the type $\mathrm{AB}$. As a result of such overlapping and electron transfer from the reductant $d$ orbital to the antibonding orbital the bond between $\mathrm{A}$ and $\mathrm{B}$ atoms is weakened.

It is obvious that $d$ orbitals can participate in all types of overlapping. The $d$ orbitals are reasonably diffuse in comparison with $s$ and $p$ penetrating orbitals. Thus, reductants and oxidants react fairly fast via $d$ orbitals. Oxidants acting via $d$ orbitals include the following: $\mathrm{Cu}^{2+}, \mathrm{Ag}^{2+}, \mathrm{Mn}^{3+}$, $\mathrm{Fe}^{3+}, \mathrm{VO}_{2}^{+}, \mathrm{MoO}_{2}^{2+}, \mathrm{CrO}_{2}^{2+}, \mathrm{MnO}_{4}^{-}, \mathrm{OsO}_{4}$ etc.; reductants acting via $d$ orbitals include: $\mathrm{Cr}^{2+}, \mathrm{Fe}^{2+}, \mathrm{Ti}^{3+}, \mathrm{V}^{3+}, \mathrm{VO}^{2+}$.

The oxidants and reductants react rather slowly via $s$ and $p$ orbitals. These oxidants include: $\mathrm{H}_{2} \mathrm{O}_{2}, \mathrm{NO}_{3}^{-}, \mathrm{ClO}_{3}^{-}, \mathrm{BrO}_{3}^{-}, \mathrm{S}_{2} \mathrm{O}_{8}^{2-}, \mathrm{ClO}_{4}^{-}$etc. The corresponding reductants are $: \mathrm{Cl}^{-}, \mathrm{Br}^{-}, \mathrm{I}^{-}, \mathrm{HS}^{-}, \mathrm{Sn}^{2+}, \mathrm{SO}_{3}^{2-}, \mathrm{ArNH}_{2}, \mathrm{ArOH}$ etc.

As can be seen in Tables 1.2 and 3, this classification is in fairly good agreement with experimental data.

The oxidants and reductants interact rather fast via $d$ orbitals, while the $d$ oxidants (the oxidants interacting via $d$ orbitals) react relatively slowly with ' $s, p$ reductants' (the reductants interacting via $s, p$ orbitals). The $d$ oxidants also react slowly with some polyatomic species.

The reactions between polyatomic ' $s, p$ oxidants' and ' $s, p$ reductants' proceed extremely slowly. It is in these cases that chemists use different catalysts to increase the reaction rate. 
Table 1. Rate of interaction between $d$ oxidants and monatomic reductants

\begin{tabular}{|c|c|c|c|c|c|c|}
\hline \multirow[t]{2}{*}{ Oxidants } & \multicolumn{6}{|c|}{ Reductants } \\
\hline & $\mathrm{Cr}^{2+}$ & $\mathrm{Fe}^{2+}$ & $\mathrm{Ti}^{3+}$ & $\mathrm{Cu}^{\mathrm{I}}$ & $\mathrm{Sn}^{2+}$ & $\mathbf{I}^{-}$ \\
\hline $\mathrm{Mn}^{3+}$ & fast & fast & fast & - & fast & - \\
\hline $\mathrm{Fe}^{3+}$ & fast & slow & fast & fast & slow & slow \\
\hline $\mathrm{Cu}^{2+}$ & - & - & - & - & - & slow \\
\hline $\mathrm{Ce}^{4+}$ & - & fast & - & 一 & fast & - \\
\hline $\mathrm{VOOH}^{2+}$ & fast & fast & fast & - & fast & average \\
\hline $\mathrm{CrO}_{4}^{2-}$ & fast & fast & - & - & fast & - \\
\hline $\mathrm{MnO}_{4}^{-}$ & - & fast & 一 & - & fast & fast \\
\hline
\end{tabular}

Table 2. Rate of oxidation of polyatomic species by $d$ oxidants

\begin{tabular}{|c|c|c|c|c|c|c|c|c|c|c|}
\hline \multirow[t]{2}{*}{ Oxidants } & \multicolumn{10}{|c|}{ Reductants } \\
\hline & $\mathrm{Hg}_{2}^{2+}$ & $\mathrm{H}_{2} \mathrm{PO}_{3}^{-}$ & $\mathrm{AsO}_{2}^{-}$ & $\mathrm{SO}_{3}^{2-}$ & $\mathrm{S}_{2} \mathrm{O}_{3}^{2-}$ & $\mathrm{C}_{2} \mathrm{O}_{4}^{2-}$ & Ascorb. & $\mathrm{N}_{2} \mathrm{H}_{4}$ & $\mathrm{ArOH}$ & $\mathrm{ArNH}_{2}$ \\
\hline $\mathrm{Mn}^{3+}$ & - & 一 & fast & - & - & fast & fast & fast & fast & fast \\
\hline $\mathrm{Fe}^{3+}$ & fast & - & slow & - & slow & - & fast & - & - & - \\
\hline $\mathrm{Cu}^{2+}$ & - & - & fast & slow & - & - & - & - & - & - \\
\hline $\mathrm{Ce}^{4+}$ & slow & slow & slow & - & fast & slow & fast & slow & - & - \\
\hline $\mathrm{VOOH}^{2+}$ & fast & slow & slow & slow & slow & - & fast & average & slow & slow \\
\hline $\mathrm{CrO}_{4}^{2-}$ & $一$ & - & slow & slow & - & - & fast & - & - & - \\
\hline $\mathrm{MnO}^{+}$ & slow & slow & slow & average & fast & slow & - & - & - & - \\
\hline
\end{tabular}


THE ROLE OF COORDINATION IN CATALYTIC REDOX PROCESSES

Table 3. Rate of oxidation of $s, p$ reductants and $\mathrm{Fe}^{2+}$ by $s, p$ polyatomic species

\begin{tabular}{llllll}
\hline \multicolumn{1}{c}{ Oxidants } & $\mathrm{Fe}^{2+}$ & $\mathrm{Sn}^{2+}$ & $\begin{array}{c}\text { Reductants } \\
\mathrm{I}^{-}\end{array}$ & AsO & Ascorb. \\
\hline $\mathrm{ClO}_{3}^{-}$ & slow & slow & slow & slow & slow \\
$\mathrm{BrO}_{3}^{-}$ & - & - & slow & slow & - \\
$\mathrm{OO}_{3}^{-}$ & - & - & - & slow & slow \\
$\mathrm{ClO}_{4}^{-}$ & - & slow & slow & slow & slow \\
$\mathrm{H}_{2} \mathrm{O}_{2}$ & - & - & slow & slow & - \\
$\mathrm{S}_{2} \mathrm{O}_{8}^{2-}$ & - & - & slow & slow & - \\
\hline
\end{tabular}

The catalysts used in different redox reactions have some remarkable features (see Table 4). The same group of substances exhibits catalytic properties in the reactions with different reductants and the same oxidant. In the case of oxidation of different reductants by hydrogen peroxide in an acid medium the substances forming coordination compounds with $\mathrm{H}_{2} \mathrm{O}_{2}, \mathrm{Ti}(\mathrm{IV}), \mathrm{Zr}(\mathrm{IV}), \mathrm{Hf}(\mathrm{IV}), \mathrm{Fe}(\mathrm{III}), \mathrm{Nb}(\mathrm{v}), \mathrm{Ta}(\mathrm{v}), \mathrm{Mo}(\mathrm{VI}), \mathrm{W}(\mathrm{vI})$, act as catalysts. Reactions with halogens are catalysed by vanadium, ruthenium, rhenium and osmium compounds. All these compounds in lower oxidation states react with halogens rather rapidly. By analogy, the arsenic, iron and vanadium compounds catalyse many reactions involving the persulphate ion.

Table 4. Catalysts used in some redox processes

\begin{tabular}{|c|c|c|c|c|c|}
\hline \multirow[t]{2}{*}{ Oxidants } & \multicolumn{5}{|c|}{ Reductants } \\
\hline & $\mathrm{I}^{-}$ & $\mathrm{S}_{2} \mathrm{O}_{3}^{2-}$ & $\mathrm{AsO}_{2}^{-}$ & $\mathrm{ArOH}$ & $\mathrm{ArNH}_{2}$ \\
\hline $\mathrm{Fe}^{3+}$ & - & $\mathrm{Cu}^{2+}$ & - & - & - \\
\hline $\mathrm{Ce}^{4+}$ & - & - & Os, I & -- & - \\
\hline $\mathrm{MnO}_{4}^{-}$ & $\overline{7 r}$ & $\overline{7 x} \bar{x}$ & Os & - & - \\
\hline $\mathrm{H}_{2} \mathrm{O}_{2}$ & $\begin{array}{l}\text { Ti, Zr, Hf, } \\
\text { Fe, Nb, Ta, } \\
\quad \text { Mo, W }\end{array}$ & $\begin{array}{l}\text { Ti, Zr, Hf, } \\
\text { V, Nb, Ta, } \\
\text { Mo, w }\end{array}$ & - & - & $\mathrm{Cu}, \mathrm{Fe}, \mathrm{Ru}, \mathrm{Os}$ \\
\hline $\mathrm{S}_{2} \mathrm{O}_{8}^{2-}$ & $\mathrm{Ag}, \mathrm{Fe}, \mathrm{V}$ & - & - & $\mathrm{Ag}, \mathrm{Fe}, \mathrm{V}$ & $\mathrm{Ag}, \mathrm{Fe}, \mathrm{V}$ \\
\hline $\mathrm{ClO}_{3}^{-}$ & $\begin{array}{l}\mathrm{V}, \mathrm{Ru}, \mathrm{Re} \\
\mathrm{Os}\end{array}$ & - & - & $\mathrm{V}, \mathrm{Ru}, \mathrm{Os}$ & $\mathrm{V}, \mathrm{Ru}, \mathrm{Os}$ \\
\hline $\mathrm{BrO}_{3}^{-}$ & $\mathrm{V}$ & - & - & V, Mo & $\mathrm{V}, \mathrm{Mo}, \mathrm{Ru}$ \\
\hline $\begin{array}{l}\mathrm{IO}_{3}^{-} \\
\mathrm{IO}_{4}^{-}\end{array}$ & $\overline{\mathrm{Ru}}$ & & I & & $\mathrm{Mn}, \mathrm{V}, \mathrm{Ru}, \mathrm{Ir}$ \\
\hline
\end{tabular}

A large number of oxidations of arsenic(III) are catalysed by osmium and iodine compounds.

It is possible to divide rather schematically and roughly all catalytic redox reactions into two groups according to their mechanisms:

1. Reactions involving the formation of an intermediate complex between catalysts and reactants.

2. Compensative reactions, involving an alternate oxidation and reduction of the catalyst. 


\section{K. B. YATSIMIRSKII}

The mechanism of the initial formation of the intermediate complex is as follows:

$$
\begin{gathered}
\mathrm{A}+\mathrm{K} \underset{k_{k-1}}{\stackrel{k_{1}}{\rightleftarrows}} \mathrm{KA} \\
{[\mathrm{KA}]=\beta[\mathrm{A}][\mathrm{K}]} \\
\mathrm{KA}+\mathbf{B} \underset{k_{2}}{\rightarrow} \mathrm{X}+\mathrm{Y}+\mathrm{K}
\end{gathered}
$$

The overall reaction is :

$$
\mathrm{A}+\mathrm{B}=\mathrm{X}+\mathrm{Y}
$$

The rate of reaction 6 may be expressed as:

$$
\mathrm{d} x / \mathrm{d} t=k_{2}[\mathrm{KA}][\mathrm{B}]
$$

Taking into account equations 5 and $5 \mathrm{a}$ we obtain:

$$
\mathrm{d} x / \mathrm{d} t=k_{2} \beta C_{k}[\mathrm{~A}][\mathrm{B}] /(1+\beta[\mathrm{A}])
$$

where $C_{k}=[\mathrm{K}]+[\mathrm{KA}]-$ the total concentration of the catalyst equation 8 may be converted into:

$$
\mathrm{d} x / \mathrm{d} t=k^{\prime} C_{k}[\mathrm{~A}][\mathrm{B}]
$$

if $\beta[\mathrm{A}] \ll 1 \quad\left(k^{\prime}=k_{2} \beta\right)$

or into

if $\beta[\mathrm{A}] \gg 1$.

$$
\mathrm{d} x / \mathrm{d} t=k_{2} C_{k}[\mathrm{~B}]
$$

Many redox processes obey equation 8 and, consequently, either equations 9 or 10 in extreme cases.

The oxidations of different substrates by hydrogen peroxide may be examples of catalytic processes involving formation of an intermediate complex.

Iodide is oxidized to free iodine in an acid medium according to the equation

$$
\mathrm{H}_{2} \mathrm{O}_{2}+2 \mathrm{I}^{-}+2 \mathrm{H}^{+}=2 \mathrm{H}_{2} \mathrm{O}+\mathrm{I}_{2}
$$

The kinetic equation in this case is

$$
\mathrm{d}\left[\mathrm{I}_{2}\right] / \mathrm{d} t=k C_{k}\left[\mathrm{H}_{2} \mathrm{O}_{2}\right]\left[\mathrm{I}^{-}\right]
$$

Here the following catalysts may be used: $\operatorname{Mo}(\mathrm{IV})\left(k=2.3 \times 10^{6}{ }^{10}\right)$, W(VI) $\left(k=1.8 \times 10^{6} 11\right), \quad \mathrm{Fe}(\mathrm{III}) \quad\left(k=1.7 \times 10^{412}\right), \mathrm{Nb}(\mathrm{V})\left(k=10^{413}\right)$, Th(IV), $\left(k=5 \times 10^{314}\right)$.

As zirconium(IV) and hafnium(IV) form reasonably stable complexes with hydrogen peroxide $\left(\beta\left[\mathrm{H}_{2} \mathrm{O}_{2}\right] \gg 1\right)$, the kinetic equation becomes similar to $10^{15,16}$ :

$$
\mathrm{d}\left[\mathrm{I}_{2}\right] / \mathrm{d} t=k C_{k}\left[\mathrm{I}^{-}\right]
$$

The rate equation for the oxidation of thiosulphate by hydrogen peroxide in an acid medium has the same form as 9 :

$$
\begin{gathered}
4 \mathrm{H}_{2} \mathrm{O}_{2}+\mathrm{S}_{2} \mathrm{O}_{3}^{2-}=3 \mathrm{H}_{2} \mathrm{O}+2 \mathrm{SO}_{4}^{2-}+2 \mathrm{H}^{+} \\
\mathrm{d}\left[\mathrm{SO}_{4}^{2-}\right] / \mathrm{d} t=k C_{k}\left[\mathrm{H}_{2} \mathrm{O}_{2}\right]\left[\mathrm{S}_{2} \mathrm{O}_{3}^{2-}\right]
\end{gathered}
$$

where $k=2.2 \times 10^{3}$ for tungsten $(\mathrm{VI}){ }^{17}$ and $k=6 \times 10^{5}$ for vanadium(v) ${ }^{18}$. 
THE ROLE OF COORDINATION IN CATALYTIC REDOX PROCESSES

The mechanism of compensative reactions can be represented in the following way:

$$
\begin{aligned}
& \mathrm{A}+\mathrm{K} \stackrel{k_{1}}{\rightarrow} \mathrm{X}+\mathrm{K}^{*} \\
& \mathrm{~K}^{*}+\mathrm{B} \stackrel{k_{2}}{\rightarrow} \mathrm{Y}+\mathrm{K}
\end{aligned}
$$

As the rates of reactions 16 and 17 must be the same, we obtain

$$
\mathrm{d} x / \mathrm{d} t=k_{1} k_{2} C_{k}[\mathrm{~A}][\mathrm{B}] /\left\{k_{1}[\mathrm{~A}]+k_{2}[\mathrm{~B}]\right\}
$$

This equation may be converted into

$$
\begin{gathered}
\mathrm{d} x / \mathrm{d} t=k_{1} C_{k}[\mathrm{~A}], \quad \text { if } \quad k_{2}[\mathrm{~B}]>k_{1}[\mathrm{~A}] \\
\text { or into } \mathrm{d} x / \mathrm{d} t=k_{2} C_{k}[\mathrm{~B}], \quad \text { if } \quad k_{1}[\mathrm{~A}]>k_{2}[\mathrm{~B}] .
\end{gathered}
$$

Many reactions proceed according to the compensative reaction mechanism, in particular the oxidation of mercury(I) by cerium(IV) in the presence of iridium(III) [or iridium(IV)] compounds as catalysts ${ }^{19}$ :

$$
\begin{gathered}
\mathrm{Ce}^{4+}+\mathrm{IrCl}_{6}^{3-}=\mathrm{Ce}^{3+}+\mathrm{IrCl}_{6}^{2-} \\
2 \mathrm{IrCl}_{6}^{2-}+\mathrm{Hg}_{2}^{2+} \rightarrow 2 \mathrm{IrCl}_{6}^{3-}+2 \mathrm{Hg}^{2+}
\end{gathered}
$$

The reaction between bromate and iodide in the presence of vanadium compounds as catalysts also proceeds by the compensative reaction mechanism $^{20}$ :

$$
\begin{aligned}
\mathrm{BrO}_{3}^{-}+6 \mathrm{H}^{+}+6 \mathrm{~V}(\mathrm{IV}) & \rightarrow \mathrm{Br}^{-}+6 \mathrm{~V}(\mathrm{~V})+3 \mathrm{H}_{2} \mathrm{O} \\
2 \mathrm{~V}(\mathrm{~V})+2 \mathrm{I}^{-} & \rightarrow 2 \mathrm{~V}(\mathrm{IV})+\mathrm{I}_{2}
\end{aligned}
$$

It is possible to study the kinetics of reactions 23 and 24 separately and to obtain a kinetic equation identical to that for the overall catalytic process:

$$
\mathrm{BrO}_{3}^{-}+6 \mathrm{H}^{+}+6 \mathrm{I}^{-} \overrightarrow{\vec{v}} \mathrm{Br}^{-}+3 \mathrm{I}_{2}+3 \mathrm{H}_{2} \mathrm{O}
$$

The mononuclear species, $\mathrm{VO}_{2}^{+}$and $\mathrm{HVO}_{3}$, have more pronounced catalytic activity than does the binuclear species, $\mathrm{H}_{3} \mathrm{~V}_{2} \mathrm{O}_{7}^{-}$. The rate constants in the reactions catalysed by these species are as follows: $1.25 \times 10^{3}$ for $\mathrm{VO}_{2}^{+}, 1.7 \times 10^{2}$ for $\mathrm{HVO}_{3}$ and 0.96 for $\mathrm{H}_{3} \mathrm{~V}_{2} \mathrm{O}_{7}^{-21}$.

In the oxidation of $p$-phenylenediamine by iodate, polynuclear species of tungstic acid have catalytic activities ten times smaller than those of mononuclear species ${ }^{22}$.

Sometimes, however, the cataly tic activities of binuclear species, especially for platinum metals, can be greater than the catalytic activities of mononuclear species.

The catalytic activities of coordination compounds in reactions of the compensative type depend on the nature of the ligands. For example, the reaction between periodate and iodide:

$$
\mathrm{IO}_{4}^{-}+8 \mathrm{I}^{-}+8 \mathrm{H}^{+} \rightarrow 4 \mathrm{I}_{2}+4 \mathrm{H}_{2} \mathrm{O}
$$

is catalysed by iridium compounds of the type $\operatorname{IrCl}_{6-n}(\mathrm{OH})_{n}{ }^{23}$. 


\section{K. B. YATSIMIRSKII}

The catalytic activities of the iridium compounds depend on the number of hydroxylic groups, $n$, in the inner sphere of complexes. The relative catalytic activities can be expressed by the rate constants: $k_{0}=0$ for $\mathrm{IrCl}_{6}^{2-}$, $k_{1}=1.53$ for $\mathrm{IrCl}_{5} \mathrm{OH}^{2-}, k_{2}=1.54$ for $\operatorname{IrCl}_{4}(\mathrm{OH})_{2}^{2-}, k_{3}=3.07$ for $\operatorname{IrCl}_{3}(\mathrm{OH})_{3}^{2-}, k_{4}=13.21$ for $\operatorname{IrCl}_{2}(\mathrm{OH})_{4}^{2-}$.

The catalyst which changes its oxidation states in the course of a redox process must have a redox potential intermediate between that of the main oxidants and reductants.

Mechanisms of the compensative type are fairly easy to understand; the catalytic processes proceed via two fairly fast reactions instead of one relatively slow basic reaction. The overall process takes place through a new pathway with either a lower activation energy or a higher activation entropy.

In considering the mechanism of formation of the intermediate complex the most important problem is that of the changes which take place in the coordinated ligands.

As a rule, the coordination of ligands by cations suppresses the ligandreducing ability and enhances the oxidizing properties. It is known that coordination of $\mathrm{S}_{2} \mathrm{O}_{3}^{2-}$ by $\mathrm{Cd}^{2+}$ and other ions makes impossible its oxidation by $\mathrm{Fe}^{3+}$ and some other oxidants ${ }^{24}$. The oxidation of $\mathrm{SO}_{3}^{2-}, \mathrm{EDTA}^{4-}$, $\mathrm{C}_{2} \mathrm{O}_{4}^{2-}$ by different oxidants is more difficult in the presence of the complexforming cations ${ }^{25-27}$. In all these cases the cations coordinate the ligands via undivided electron pairs (non-bonded orbitals) and this reaction site therefore becomes inaccessible to oxidants.

Cases are known, however, where coordination enhances the reducing ability of molecules or ions, e.g. the thiocyanate ion is oxidized more readily hy bromate if this is coordinated to $\mathrm{Fe}^{3+}\left(\mathrm{FeNCS}^{2+}\right.$-coordination compounds) ${ }^{28}$. It is reasonable to assume that the reaction centre in this compound is located on the sulphur atom while in the coordination compound it remains open to attack by a bromate ion. The positive charge of the complex facilitates the approach of $\mathrm{BrO}_{3}^{-}$to the reductant.

Let us consider now the mechanisms of action of catalysts in redox reactions in general. In the simplest cases the catalyst facilitates the approach of particles with the same electric charge. For example, the hexammine cobalt(III) ion enhances the rate of the reaction between persulphate and iodide ${ }^{29}$. This is the case when outer sphere complex formation is only possible between $\mathrm{Co}\left(\mathrm{NH}_{3}\right)_{6}^{3+}$ and $\mathrm{I}^{-}$and $\mathrm{S}_{2} \mathrm{O}_{3}^{2-}$. The alkali metal cations increase the rate of reaction of $\mathrm{MnO}_{4}^{-}$with $\mathrm{MnO}_{4}^{2-}$ in the order: $\mathrm{Na}^{+}<$ $\mathrm{Rb}^{+}<\mathrm{K}^{+}<\mathrm{Cs}^{+30}$.

A more complicated case is the formation of the bridge-activated complex between metal ions involving the 'catalyst' as an ion or molecule ${ }^{31}$. The action of the bridge-forming species is more complicated than a simple electrostatic interaction as formation of the three-centre molecular orbital is possible only if essential changes take place in the electron density distribution.

Now we return to the consideration of changes in the ligands due to coordination. The coordinated particles have essentially different charge distributions, bond energies and orbital populations compared with those of free particles. Three types of coordination, linear, angle and perpendicular, have been established for the simplest diatomic molecules ${ }^{32}$, Figure 2. 
THE ROLE OF COORDINATION IN CATALYTIC REDOX PROCESSES

Different types of coordination of $A B$-molecule

$$
M=\mathrm{A}=\mathrm{B} \quad \mathrm{M}=\mathrm{A}
$$

Figure 2. Types of diatomic molecule coordination

Let us begin to discuss the linear configuration first. According to the electrostatic theory, the dipole moment of the $\mathrm{AB}$ particle in such a coordination compound must be greater than in a free particle due to the attraction of the negative pole, A, and the repulsion of the positive pole, B, Figure 3. As the positive pole repels the $\mathrm{AB}$ bond weakens and heterolytic fission of this bond can more readily occur. The reaction centre, B, becomes more electropositive and, therefore, more appropriate for nucleophilic attack.

The mechanisms of ligand activation

$$
\stackrel{n+\delta-\delta+}{M} \stackrel{\delta--B}{\rightarrow} \quad \text { Electrostatic interaction } \quad \mu_{C}>\mu_{F}
$$$$
\begin{array}{ll}
n-\delta-q_{A}+\delta_{1}+q_{B}+\delta_{2} \\
M \leftarrow A \leftarrow-B
\end{array}
$$
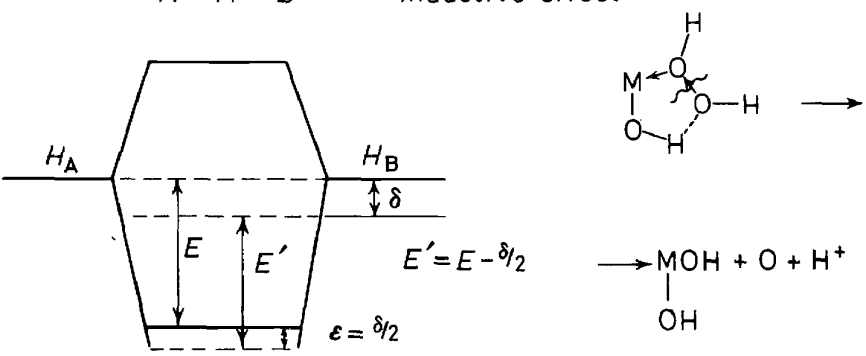

Figure 3. The interaction in coordinated diatomic molecules

From the point of view of the valence bond theory, there is thus a considerable effect. As a consequence of this effect, the positive charge of the metal atom and the negative charge on the $\mathrm{A}$ atom decrease, while the positive charge on the $\mathbf{B}$ atom increases. It facilitates the heterolytic fission of the $A B$ bond and makes nucleophilic attack on the B atom more effective.

At last, it is evident on the simplest basis of MO theory that due to including the nonbonding orbital of the A atom into the $\mathrm{M}-\mathrm{A}$ bond and partial charge transfer in the direction of the $\mathrm{M}$ atom, the difference in coulombic integrals of the A and B orbitals becomes greater and, as a result, the bonding energy becomes smaller (Figure 3 ). Thus, from a third point of view we obtain 


\section{K. B. YATSIMIRSKII}

the same results: the $A-B$ bond weakens and heterolytic fission of this bond becomes possible.

To illustrate such an induced heterolytic fission, the formation of coordination compounds of metals in high oxidation states by the action of hydrogen peroxide can be mentioned. The heterolytic fission of the $\mathrm{O}-\mathrm{O}$ bond yields a very unstable $\mathrm{OH}^{+}$ion, which is immediately converted into a solvated proton and an $\mathrm{O}$ atom. A cyclic structure is favoured by this process and hydrolysed species such as $\mathrm{ThOH}^{3+}, \mathrm{Hf}(\mathrm{OH})_{3}^{+}, \mathrm{Zr}(\mathrm{OH})_{3}^{+}$, rather than free cations, $\mathrm{Th}^{4+}, \mathrm{Hf}^{4+}, \mathrm{Zr}^{4+}$ and the like are thus inherent in high catalytic activity ${ }^{14,33}$.

The bond distances in coordinated species become slightly longer in comparison with those of the corresponding free species, but this effect is fairly small (Table 5).

Table 5. Bond distances in free and coordinated species, $\AA$ [ref. 4]

\begin{tabular}{lllll}
\hline Bond & \multicolumn{2}{c}{ Free species } & \multicolumn{2}{c}{ Coordinated species } \\
\hline $\mathrm{C}-\mathrm{O}$ & 1.44 & $\left(\mathrm{CH}_{3}\right)_{2} \mathrm{O}$ & 1.45 & $\mathrm{BF}_{3}\left(\mathrm{CH}_{3}\right)_{2} \mathrm{O}$ \\
$\mathrm{C}=\mathrm{O}$ & 1.13 & $\mathrm{CO}$ & 1.15 & $($ in carbonyl) \\
$\mathrm{NO}-\mathrm{O}$ & 1.23 & $\mathrm{NaNO}_{2}$ & 1.26 & $\mathrm{Co}\left(\mathrm{NH}_{3}\right)_{3}\left(\mathrm{NO}_{2}\right)_{3}$ \\
\hline
\end{tabular}

In some rather simple cases it is possible to carry out quantum-mechanical calculations of some parameters characterizing the coordinated molecules. As an example, we chose the coordination of the nitrogen molecule, $\mathbf{N}_{2}$. These calculations are undoubtedly connected with another problem-that of nitrogen fixation involving two stages: activation of the nitrogen molecule and the interaction of this molecule with hydrogen. The latter is effectively a redox reaction :

$$
\mathrm{N}_{2}+3 \mathrm{H}_{2}=2 \mathrm{NH}_{3}
$$

The activation of the nitrogen molecule can be accomplished by its coordination by a transition metal atom. All known catalysts used in this process include a transition metal as one component. The biological catalysts also involve nitrogen molecule coordination. Several coordination compounds containing the $\mathrm{N}_{2}$ molecule as a ligand have been obtained during recent years.

We calculated some three-centre fragments of the coordination compounds of $\mathrm{N}_{2}$ with $3 d$ metal atoms (first transition series). For this purpose we used the extended Hückel method proposed by Hoffmann and modified by other authors $^{34,35}$.

Two geometrical arrangements were used for a three-centre $\mathrm{MN}_{2}$ frag-

ment: linear $\mathbf{M} \ldots \mathbf{N} \equiv \mathbf{N}$ (linear complex, LC) and perpendicular $\mathbf{M} . . \|$

(perpendicular complex, PC).

The orbital sequence in $\mathrm{FeN}_{2}$ complexes is shown in Figure $4^{36,37}$.

The metals in the middle of the fourth period, $\mathrm{Cr}, \mathrm{Mn}, \mathrm{Fe}, \mathrm{Co}, \mathrm{Ni}$, are especially interesting from practical and theoretical points of view. For 


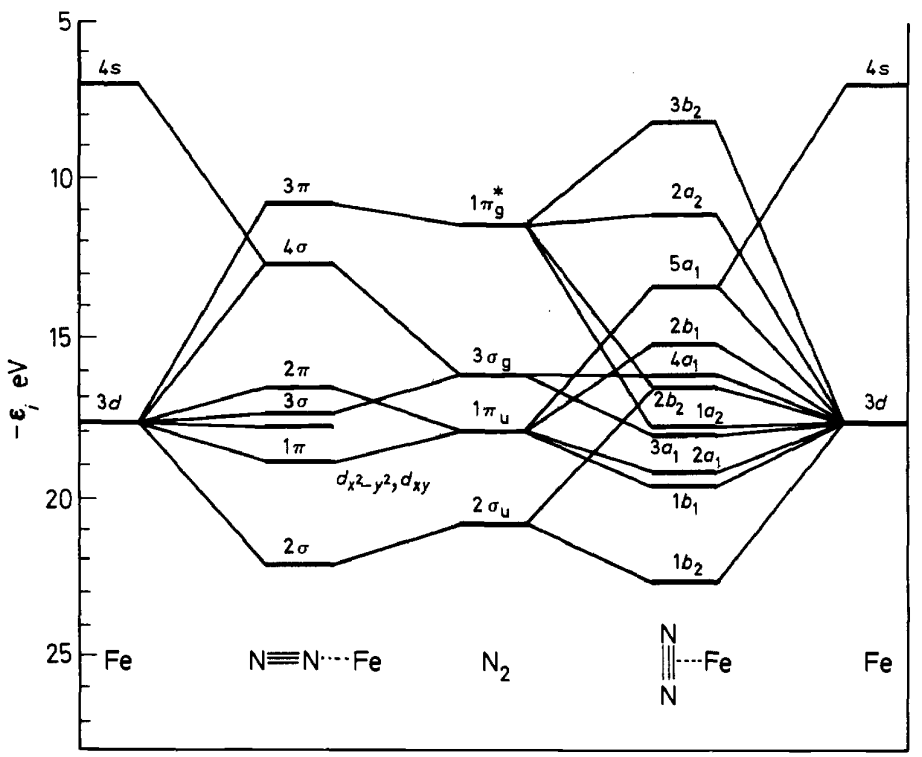

Figure 4. Correlation diagrams for $\mathrm{FeN}_{2}$ complexes

these $\mathrm{MN}_{2}$ compounds the $2 \pi$ and $4 \sigma$ orbitals are filled up in LC and the $2 b_{2}$ and $5 a$ orbitals are filled up in PC.

We suppose that the $\mathrm{N}-\mathrm{N}$ distances are constant in all complexes $\left(R_{\mathrm{N}-\mathrm{N}}\right.$ is $\left.1.142 \AA\right)$. The value of the Co-N distance was taken from experimental data ${ }^{38}$. All other $\mathbf{M}-\mathrm{N}$ distances were calculated on the basis of this value taking into account the atomic radii of other $\mathrm{M}$ atoms.

At the beginning of the first row of transition metals the perpendicular complexes are more stable than the linear ones but in the middle of the row LC is energetically more advantageous than PC. For $\mathrm{FeN}_{2}$ the linear complex is more stable than the perpendicular one within all $\mathbf{M}-\mathbf{N}$ distances (Figure $5^{36}$, Table 6).

The total $\mathbf{N}-\mathbf{N}$ bond population decreases in coordination compounds in comparison with that of a free $\mathrm{N}_{2}$ molecule. The decrease is especially marked in PC. In both cases (LC and PC) the $\pi$ bond population decreases

Table 6. Ionization and dissociation energies of $\mathrm{MN}_{2}$ complexes

\begin{tabular}{|c|c|c|c|c|c|}
\hline & $M \ldots N \equiv N$ & LC & $\mathbf{M}$ & PC & \\
\hline $\mathbf{M}$ & I & D & I & D & $\Delta D(\mathrm{PC}-\mathrm{LC})$ \\
\hline $\mathrm{Cr}$ & 15.1 & 23.8 & 14.7 & 25.5 & 1.7 \\
\hline $\mathrm{Mn}$ & 16.3 & 28.0 & 14.6 & 27.4 & -0.6 \\
\hline $\mathrm{Fe}$ & 16.6 & 27.2 & 15.1 & 25.2 & -2.0 \\
\hline Co & 13.7 & 24.0 & 14.4 & 23.1 & -0.9 \\
\hline $\mathrm{Ni}$ & 14.6 & 21.1 & 15.2 & 21.3 & 0.2 \\
\hline
\end{tabular}




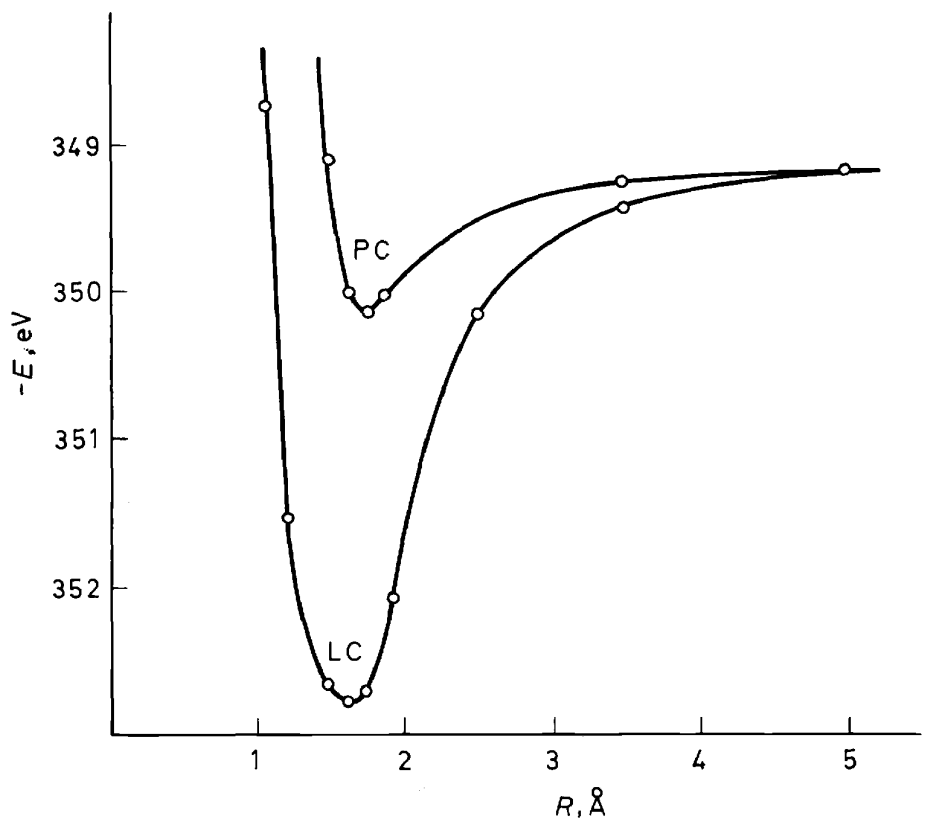

Figure 5. Potential energy curves for the linear and perpendicular $\mathrm{FeN}_{2}$ complexes

as compared with that of a free $\mathrm{N}_{2}$ molecule. The population of the $\sigma$ bond decreases in PC and increases in LC in comparison with that of a free $\mathrm{N}_{2}$ molecule. Table 8 shows the electron promotion in complexes involving $\mathrm{N}_{2}$ molecules of different types.

There is $\sigma$ displacement of electrons from the $\mathrm{N}_{2}$ molecule to the metal atom in all LC. Analogous $\sigma$ displacements of electrons are not so large or regular in perpendicular complexes. The shift of electrons in $\pi$ bonds is directed to metal atoms for chromium and manganese while for iron, cobalt and nickel atoms such movement takes place in the opposite direction.

Table 7. $\sigma, \pi$ bond population in $\mathrm{MN}_{2}$ complexes of different types

\begin{tabular}{|c|c|c|c|c|c|c|}
\hline & \multicolumn{2}{|c|}{$\stackrel{\mathbf{N}-\mathbf{N}}{\text { in linear complexes }}$} & \multirow[b]{2}{*}{$n_{\mathrm{\sigma}+\pi}$} & \multicolumn{3}{|c|}{$\stackrel{\mathrm{N}-\mathrm{N}}{\text { in perpendicular complexes }}$} \\
\hline & $n_{\sigma}$ & $n_{\pi}$ & & $n_{0}$ & $n_{\pi}$ & $n_{\sigma+\pi}$ \\
\hline $\mathbf{M}$ & 0.796 & 0.816 & 1.612 & 0.796 & 0.816 & 1.612 \\
\hline $\mathrm{Cr}$ & 0.838 & 0.577 & 1.415 & 0.731 & 0.238 & 0.969 \\
\hline $\mathrm{Mn}$ & 0.821 & 0.634 & 1.455 & 0.733 & 0.384 & 1.117 \\
\hline $\mathrm{Fe}$ & 0.809 & 0.747 & 1.556 & 0.738 & 0.524 & 1.262 \\
\hline Co & 0.807 & 0.778 & 1.585 & 0.797 & 0.635 & 1.432 \\
\hline $\mathrm{Ni}$ & 0.825 & 0.795 & 1.620 & 0.852 & 0.757 & 1.609 \\
\hline
\end{tabular}


Table 8. Electron promotion in $\mathrm{MN}_{2}$ complexes

\begin{tabular}{|c|c|c|c|c|c|}
\hline \multirow{2}{*}{ Metals } & \multicolumn{5}{|c|}{ Linear complexes $\mathbf{N}^{\prime} \mathbf{N}^{\prime \prime} \mathbf{M}$} \\
\hline & $\mathrm{N}_{\sigma}^{\prime}$ & $\mathrm{N}_{\sigma}^{\prime \prime}$ & M & $\mathbf{N}_{\pi}^{\prime}$ & $\mathbf{N}_{\pi}^{\prime \prime}$ \\
\hline $\mathrm{Cr}$ & -0.023 & -0.579 & +0.602 & +0.005 & -0.093 \\
\hline Mn & -0.069 & -0.781 & +0.850 & +0.044 & -0.246 \\
\hline $\mathrm{Fe}$ & -0.102 & -0.815 & +0.917 & +0.398 & -0.129 \\
\hline $\mathrm{Co}$ & -0.092 & -0.518 & +0.610 & +0.265 & -0.103 \\
\hline $\mathrm{Ni}$ & +0.001 & -0.114 & +0.113 & +0.173 & -0.078 \\
\hline \multirow[t]{2}{*}{ Metals } & \multicolumn{5}{|c|}{ Perpendicular complexes } \\
\hline & M & $\mathbf{N}_{\sigma}$ & $\mathbf{M}_{\sigma}$ & $\mathbf{N}_{\pi}$ & $\mathrm{M}_{\pi}$ \\
\hline $\mathrm{Cr}$ & +0.088 & +0.194 & -0.388 & -0.186 & +0.372 \\
\hline Mn & +0.202 & -0.081 & +0.162 & -0.182 & +0.364 \\
\hline $\mathrm{Fe}$ & -0.269 & -0.173 & +0.346 & +0.036 & -0.072 \\
\hline $\mathrm{Co}$ & -0.162 & -0.097 & +0.194 & +0.020 & -0.040 \\
\hline $\mathrm{Ni}$ & -0.095 & +0.098 & -0.196 & +0.012 & -0.024 \\
\hline
\end{tabular}

\section{REFERENCES}

1 W. A. Waters, Mechanisms of Oxidation of Organic Compounds, Methuen: London (1964).

2 R. Stewart, Oxidation Mechanisms, Benjamin: New York (1964).

3 T. A. Turney, Oxidation Mechanisms, Butterworths: London (1965).

${ }^{4}$ M. M. Jones, Ligand Reactivity and Catalysis, Academic Press: New York (1968).

5 J. P. Candlin, K. A. Taylor and D. T. Thompson, Reactions of Transition Metal Complexes, Elsevier: Amsterdam (1968).

${ }^{6} \mathrm{H}$. Taube, Proceedings of the XIIth ICCC, p. 6a;

N. Sutin, Proceedings of the XIIth ICCC, $\mathrm{p} 36$.

7 L. G. Sillén and A. E. Martell, Stability Constants of Metal-Ion Complexes, Spec. Publ. No. 17, Chemical Society: London (1964).

${ }^{8}$ K. B. Yatsimirskii, Theoret. Exp. Chem., Kiev, 1, 334 (1965).

9 D. Herschbach, Advances in Chemical Physics, Vol. X, 'Molecular Beams', Part 9, Interscience Publishers-Wiley: London (1966).

${ }^{10}$ K. B. Yatsimirskii and L. P. Afanaseva, J. Analyt. Chem., Moscow, 11, 319 (1956).

${ }^{11}$ K. B. Yatsimirskii and V. l. Rigin, J. Analyt. Chem., Moscow, 13, 112 (1958).

12 K. B. Yatsimirskii and G. A. Karacheva, J. Inorg. Chem., Moscow, 3, 352 (1958).

${ }^{13}$ K. B. Yatsimirskii and V. I. Skuratov, J. Inorg. Chem., Moscow, 8, 573 (1963).

${ }^{14}$ K. B. Yatsimirskii and J. Zhukov, Radiochem., Leningrad, 466 (1961).

15 K. B. Yatsimirskii and L. P. Raizman, J. Inorg. Chem., Moscow, 5, 593 (1960).

16 K. B. Yatsimirskii and L. P. Raizman, J. Inorg. Chem., Moscow, 7, 1819 (1962).

17 K. B. Yatsimirskii and E. F. Naryshkina, J. Inorg. Chem., Moscow, 3, 346 (1958).

${ }^{18}$ K. B. Yatsimirskii and E. F. Naryshkina, J. Inorg. Chem., Moscow, 4, 1548 (1959).

19 K. B. Yatsimirskii, L. P. Tikhonova and I. P. Svarkovskaya, J. Inorg. Chem., Moscow, 14, 2982 (1969).

${ }^{20}$ K. B. Yatsimirskii and V. E. Kalinina, Izvest.Vuzov. Ser. Chem. Chem. Technol., Ivanovo, 8 , 378 (1965).

21 K. B. Yatsimirskii and V. E. Kalinina, J. Inorg. Chem., Moscow, 9, 1117 (1964).

22 K. B. Yatsimirskii and V. F. Romanov, J. Inorg. Chem., Moscow, 9, 1578 (1964).

${ }^{23}$ K. B. Yatsimirskii, V. E. Kalinina, R. P. Morozova and T. I. Fedorova, Proc. Ivanovo Chem.Technol. Inst., Ivanovo, 10, 68 (1968).

${ }^{24}$ K. B. Yatsimirskii, J. Analyt. Chem., Moscow, 10, 344 (1955).

25 M. T. Beck and O. King, Acta Chem. Scand. 15, 453 (1961). 
26 F. Feigl, Z. Analyt. Chem. 74, 389 (1928).

27 S. Zsindley and E. Pungor, Microchim. Acta, 2, 209 (1963).

28 W. I. Jendrzejewski and K. B. Yatsimirskii, J. Analyt. Chem., Moscow, 21, 314 (1966).

29 A. Indelli and E. S. Amis, J. Am. Chem. Soc. 82, 332 (1960).

30 J. C. Sheffard and A. C. Wahl, J. Am. Chem. Soc. 79, 1020 (1957).

31 H. Taube, Advanc. Chem. Ser. 49, 107 (1965).

32 J. A. Ibers, Proceedings of the XIIth ICCC, Sydney, p 198 (1970).

33 K. B. Yatsimirskii and L. P. Raizman, J. Analyt. Chem., Moscow, 18, 829 (1963).

34 R. Hoffman, J. Chem. Phys. 39, 1397 (1963).

35 G. I. Kagan, G. M. Kagan and I. N. Fundyler, Theoret. Exp. Chem., Kiev, 3, 444 (1967).

36 J. A. Kruglyak and K. B. Yatsimirskii, Theoret. Exp. Chem., Kiev, 5, 308 (1969).

${ }^{37}$ K. B. Yatsimirskii, J. P. Nazarenko, Y. I. Bratushko and J. A. Kruglyak, Theoret. Exp. Chem., Kiev, 6, 729 (1970).

38 B. R. Davis, N. V. Payne and J. A. Ibers, J. Am. Chem. Soc. 91, 1240 (1969). 